ORIGINAL ARTICLE

\title{
Empyema: the use of broad range 16S rDNA PCR for pathogen detection
}

\author{
S Saglani, K A Harris, C Wallis, J C Hartley
}

Arch Dis Child 2005;90:70-73. doi: 10.1136/adc.2003.042176

See end of article for authors' affiliations

......................

Correspondence to: DrJ C Hartley, Consultant Microbiologist, Camelia

Botnar Laboratories, Great

Ormond Street Hospital for

Children NHS Trust, Great

Ormond Street, London

WCIN 3JH, UK;

Hartlj3@gosh.nhs.uk

Accepted

18 February 2004
Background: An increase in the incidence of thoracic empyema in children has been reported. The causative pathogen is often unknown as pleural fluid is frequently sterile at the time of culture. The role of unusual organisms is unclear.

Aims: (1) To compare the detection of organisms in pleural fluid from children with empyema using a molecular technique (16S rDNA polymerase chain reaction (PCR)) and bacterial culture. (2) To compare the concordance of organisms identified using the two techniques and the influence of prior antibiotic treatment on positive detection rate.

Methods: Pleural fluid from children admitted with empyema between January 2000 and February 2002 was cultured and additionally analysed using broad range 165 rDNA PCR.

Results: Pleural fluid was cultured from 32 patients, aged 1 month-16 years. Median duration of previous antibiotic therapy was 8 days (range 1-42 days). Six samples were culture positive and 22 were PCR positive. A causal organism was detected by PCR alone, after considering results from the local hospital, in 14 patients. There was complete concordance in organisms cultured and detected by PCR. Additional organisms detected by PCR were predominantly $S$ pneumoniae, $S$ pyogenes, and anaerobes.

Conclusions: Analysis of pleural fluid by broad range 16S rDNA PCR in addition to culture, increases organism identification in empyema.
A $\mathrm{n}$ increase in the incidence of childhood empyema has been reported by several centres. ${ }^{1-5}$ Possible reasons for this include delay in initiating treatment; prolonged oral treatment in the community with antibiotics, with inadequate drug levels in the pleural space, and delayed hospital presentation; ${ }^{4}$ or unusual causal organisms. ${ }^{6}$ Streptococcus pneumoniae remains the most common causal organism of childhood empyema, ${ }^{1}{ }^{7}$ but the rate of organism isolation from pleural fluid in empyema is low, ranging from $17 \%^{8}$ to $42 \%^{4}$. Accurate knowledge of the causal organisms (and sensitivities) is important as it would allow use of narrow spectrum antibiotics with decreased cost and selection of resistance, and would identify unusual pathogens.

Some species are difficult to isolate or grow slowly in the laboratory due to stringent growth requirements, while others may not grow because of prior empirical treatment with antimicrobial agents. Molecular techniques, such as polymerase chain reaction (PCR), can aid in the diagnosis of bacterial infection. Broad range PCR, based on bacterial ribosomal DNA (rDNA), can detect all bacterial species in a single assay, saving time and money as well as identifying unusual or unexpected causal agents. With this molecular technique, PCR primers are targeted at conserved regions of rDNA that flank a variable region. Nucleotide sequencing of the PCR product reveals the identity of the source organism from which the bacterial DNA came. Broad range PCR based on the 16S rDNA gene has been applied to samples from normally sterile sites to diagnose a range of bacterial infections including meningitis, bacteraemia, and osteomyelitis. ${ }^{9-14}$ A recent study has shown that broad range 16S rDNA PCR increased the diagnosis of bacterial infection in children when used alongside culture in samples from normally sterile sites. $^{15}$

We have applied an established and validated broad range 16S rDNA PCR technique to pleural fluid from children with thoracic empyema to assess the increase in diagnostic yield, to assess the range of organisms identified, and to compare concordance of organism isolation using traditional culture techniques and the molecular technique.

\section{METHODS}

\section{Subjects}

Case notes of all children with empyema where pleural fluid had been collected from our centre, and sent for both microbiological analysis and assessment by $16 \mathrm{~S}$ rDNA PCR between January 2000 and February 2002, were reviewed. Details about duration of antibiotic treatment prior to pleural fluid aspiration at our centre, and culture results from any previous aspiration at the patient's local hospital were recorded. Results of organism isolation using traditional culture were compared to organism identification using the molecular technique.

\section{Culture}

All empyema samples were cultured directly and after enrichment in Robertson's cook meat broth for 24 hours on to blood, chocolate, MacConkey, and selective anaerobic agar (cycloserine and novobiocin/vancomycin) media. Plates were incubated in air, $\mathrm{CO}_{2}$ enriched atmosphere, and anaerobically for 48 hours as appropriate. Organisms were identified by routine laboratory methods. Samples were selected for mycobacterial culture when clinically indicated or no other bacterial cause was found.

\section{DNA extraction}

Pleural fluid was extracted using a previously described technique. ${ }^{15}$ DNA was extracted from the samples using the QIAmp DNA mini kit (Qiagen Ltd, West Sussex, UK), following the body fluid protocol. An additional incubation at $95^{\circ} \mathrm{C}$ for 15 minutes was performed following the proteinase $\mathrm{K}$ digestion to ensure complete lysis of bacterial cells. However, for all samples processed after 1 October 2000 this step was performed mechanically using a Ribolyser cell disrupter (Hybaid, Ashford, UK) according to manufacturer's 
instructions. One negative control (200 $\mu$ l of sterile, UV irradiated water) was included in each extraction run.

\section{PCR amplification}

Five microlitres of extracted DNA and $5 \mu \mathrm{l}$ of extracted DNA diluted $1 / 10$ were amplified with primers $16 \mathrm{SFa}, 16 \mathrm{SFb}$, and 16SR as previously described. ${ }^{15}$

\section{Sequencing}

PCR products were sequenced with the ABI PRISM Big-dye sequencing kit (PE Applied Biosystems, Warrington, UK) and analysed on the ABI 377 Genetic Analyser (PE Applied Biosystems). Sequences were compared to the Genbank database using the BLAST program available at The National Centre for Biotechnology Information (www.ncbi.nlm.nih. gov) and to an in-house database of I6S rDNA sequences using the CLUSTAL algorithm in the MEGALIGN computer program (DNAStar, Madison, WI). Criteria for bacterial identification were as previously described. ${ }^{15}$

\section{Assay sensitivity/specificity}

In silico, the 16S rDNA PCR can detect all common, known pathogens, including Mycobacterium tuberculosis. From control cultures of Escherichia coli and Staphylococcus aureus the assay can detect DNA 10-100 colony forming units/PCR reaction input. Precise details of assay performance and the genera of specific organisms that have been identified using the assay have been previously described. ${ }^{15}$

\section{Statistical analysis}

In order to calculate the sensitivity and specificity of the broad range PCR in detecting organisms in empyema, we required a reference standard against which to compare the PCR results. ${ }^{16}$ This standard is bacterial culture, but as so few samples were culture positive, this calculation was meaningless. Therefore the assay sensitivity could only be calculated based on the assumption that all patients should potentially have had organisms in their pleural fluid (and therefore should be culture positive), as they all had a clinical picture of empyema.

\section{RESULTS}

Thirty two patients were included, median age 2.9 years (range 1 month-16 years). Six patients (19\%) had pleural fluid aspiration prior to transfer to our centre; four of these $(67 \%)$ were culture positive. Patients had received a median of 8 days' (range 1-42 days) antibiotic therapy prior to fluid

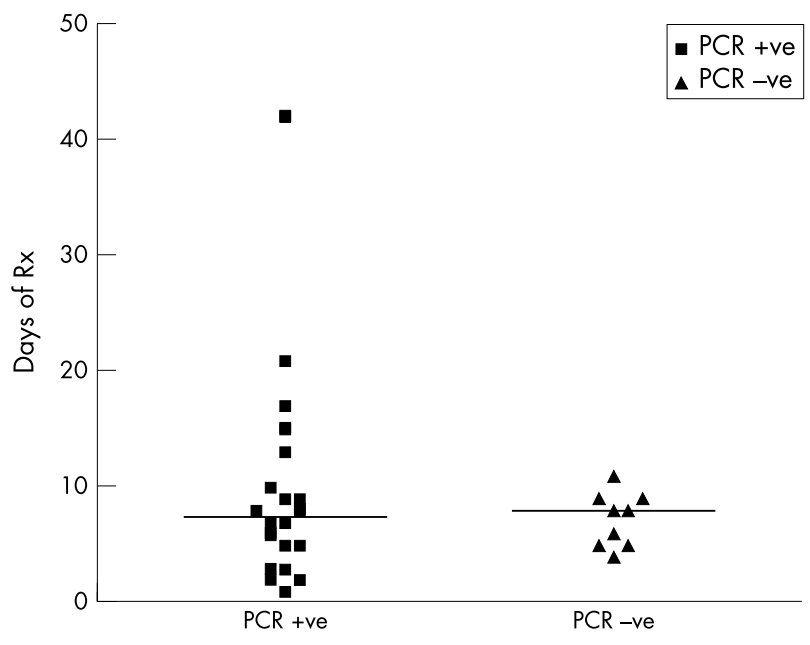

Figure 1 PCR results in relation to duration of previous antibiotic therapy in 32 samples (data missing from three patients).
Table 1 Results from 32 patients whose pleural fluid was analysed by culture at our centre

\begin{tabular}{lccc}
\hline & PCR positive & PCR negative & Total \\
\hline Culture positive & 5 & 1 & 6 \\
Culture negative & 17 & 9 & 26 \\
Total & 22 & 10 & 32 \\
\hline
\end{tabular}

aspiration at our centre (fig 1). They had all received antibiotics that would act against penicillin sensitive strains of $S$ pneumoniae; however, details of previous anti-staphylococcal therapy were not known.

For samples collected in our centre, significant organisms were cultured in $6 / 32(18.7 \%)$ cases (three $S$ aureus, one $S$ milleri, one $S$ pyogenes, one $S$ pneumoniae), whereas $22 / 32$ $(68.7 \%)$ cases were PCR positive (24 organisms identified). Pleural fluid was PCR positive and culture negative in 17/32 $(53 \%)$ cases (table 1$)$. Table 2 shows the organisms identified by PCR or culture in the 32 samples.

Four patients had a growth of coagulase negative staphylococci (three on subculture only), thought to be a contaminant growth. These were considered culture negative for the purposes of this study. Two of the four were PCR positive, both with $S$ pneumoniae, one was PCR negative, and the remaining sample revealed a mixed sequence, felt to be contaminants, and was therefore reported negative.

Five of six culture positive samples were PCR positive; the organism isolated by culture was the same as that identified using PCR in all cases; the organism not detected by PCR was a $S$ aureus grown only after enrichment culture.

Six of 32 patients had previously had pleural fluid cultured at their local hospital. Four of these patients had a positive culture result from the local hospital. Pleural fluid samples from these cases were all culture negative, but three were PCR positive at our centre. The organisms identified by PCR were the same as those isolated at the local hospital (two $S$ pneumoniae, one $S$ pyogenes).

After considering all results (local and our centre) in the PCR group, causative organisms were detected in 24/32 (75\%) cases (table 2 ). One case was only culture positive at the local hospital, and one only culture positive at our centre (table 2 ). An organism was identified by PCR alone in 14/32 (44\%) patients.

The sensitivity of 16S rDNA PCR in this series of samples (for patients who had clinical empyema, but had received antibiotics) was $22 / 32(69 \%)$. The sensitivity of culture for the same samples was $6 / 32(18.7 \%)$.

\section{DISCUSSION}

The overall rate of organism isolation using pleural fluid culture for our study was $18.7 \%$ (6/32), approximating previous reports, ${ }^{817}$ and the range of organisms cultured were in close agreement with other studies from the UK. ${ }^{18}$ Addition of broad rangel6S rDNA PCR to detect pathogens increased organism detection in pleural fluid collected at our centre from $18.7 \%(6 / 32)$ to $68.7 \%(22 / 32)$ of cases. In PCR positive samples from patients where organisms had been cultured in the referring hospital ${ }^{3}$ or in a later specimen, there was complete concordance for bacterial identity, although such cases were small in number. Even taking into account results from samples collected and processed before referral to our unit, use of 16S rDNA PCR detected causal organisms in an additional $44 \%$ of children with empyema.

The main additional organisms identified by $16 \mathrm{~S}$ rDNA PCR were $S$ pneumoniae and $S$ pyogenes. This is in agreement with the previously reported findings of a specific pneumococcal PCR being positive in the majority of a group of 
Table 2 Causative organisms detected in 32 cases of paediatric empyema, taking into account culture and PCR results from our centre and the local hospital

\begin{tabular}{|c|c|c|c|c|}
\hline \multirow[b]{3}{*}{ Organisms } & \multirow{2}{*}{\multicolumn{2}{|c|}{$\begin{array}{l}32 \text { samples processed } \\
\text { by culture and PCR } \\
\text { Method of detection }\end{array}$}} & \multicolumn{2}{|c|}{$\begin{array}{l}\text { Final diagnosis, incorporating } \\
\text { microbiology from local } \\
\text { hospital }\end{array}$} \\
\hline & & & \multirow{2}{*}{$\begin{array}{l}\text { No. of } \\
\text { patients }\end{array}$} & \multirow[b]{2}{*}{$\%$ of cases } \\
\hline & PCR & Culture & & \\
\hline Streptococcus pneumoniae & 13 & 1 & $14^{*}$ & 44 \\
\hline Streptococcus pyogenes & 3 & 1 & 3 & 13 \\
\hline Staphylococcus aureus & 2 & $3 \dagger$ & 3 & 9 \\
\hline Fusobacterium sp & 1 & 0 & 1 & 3 \\
\hline Fusobacterium, Actinomyces, and & 1 & 0 & 1 & 3 \\
\hline $\begin{array}{l}\text { Streptococcus milleri group, } \\
\text { Peptostreptococcus sp (PCR only) }\end{array}$ & 1 & $1 \ddagger$ & 1 & 3 \\
\hline No bacterial cause detected & 10 & 26 & 8 & 25 \\
\hline Total & 32 & 32 & 32 & 100 \\
\hline
\end{tabular}

children with empyema. ${ }^{7}$ However, DNA of more fastidious organisms was also detected by our broad range PCR. These were mainly anaerobic organisms, found in cases with an unusually protracted illness, which had shown a poor response to broad spectrum antibiotics. These organisms were detected using PCR, even though some of the children had the longest duration of antibiotic therapy (up to 42 days) prior to pleural fluid evaluation. The additional organisms detected by PCR were probably not cultured because of prior antibiotic treatment. ${ }^{18} S$ pneumoniae and $S$ pyogenes are usually very sensitive to penicillins (common agents used to treat respiratory infection), and may have been rendered unculturable by prior treatment. $S$ aureus is usually resistant to penicillin and may therefore have persisted. In this study there was one case in which $S$ aureus was cultured, after enrichment, but not detected by PCR. This result occurred because the organism was present at a level below the detection limit of the PCR assay. Also, one sample was both culture and PCR negative at out centre, but had been positive at the referring hospital. This is because the period of time between antibiotic administration and empyema sampling alters the culture result, as organisms are killed, and the PCR result, as subsequent DNA degradation takes place. DNA remains after organisms become non-viable by culture methods, but DNA does not persist indefinitely and PCR subsequently also becomes negative. It is therefore important to emphasise that PCR should be complementary to culture, and not used as a replacement.

An increase in penicillin resistant $S$ pneumoniae may be contributory to the increase in the incidence of empyema. However, it is possible to determine whether the organisms identified by PCR alone were penicillin sensitive, using molecular assays based on the penicillin binding protein $2 \mathrm{~B}$

\section{What is already known on this topic}

- Incidence of paediatric empyema is increasing

- The detection rate of causal organisms in pleural fluid using culture alone remains low, and the reason for the increase in incidence may be explained by unusual causal organisms

- Use of a pneumococcal specific PCR in paediatric empyema is positive in approximately two thirds of cases gene. ${ }^{19}$ This approach has been applied to a series of empyema samples ${ }^{7}$ and to a number of samples from this series (unpublished data, KA Harris). Only fully sensitive S pneumoniae were identified. This suggests that the increase in empyema rate is not predominantly due to penicillin resistant $S$ pneumoniae.

The failure of culture to detect causative organisms in the majority of empyema samples in this series is due to prior antibiotic treatment. This is important as empirical antibiotic selection is influenced by anticipated causative organisms and expected sensitivity. This information suggests there is no need for broad spectrum antibiotics but that appropriate dose and selection of agents able to penetrate the empyema, allied to drainage of pus, are more important in prevention or resolution of this infection. However, even with PCR, 25\% of the series still did not have a bacterial diagnosis. This is most likely because of previous treatment with antibiotics and bacterial DNA degradation. However, there may be other, yet undescribed organisms that were not detected. Importantly, although it appears that the PCR only has a sensitivity of $69 \%$, this is in samples from patients who have all received previous antibiotic therapy. As can be seen from fig l, cases that were PCR negative had all received at least four days of prior antibiotic therapy. Therefore, molecular analysis of samples taken earlier in the illness (especially before prolonged antibiotic use) may further increase diagnostic yield. Also, the assay sensitivity could only be calculated based on the assumption that all pleural fluid samples should

\section{What this study adds}

- First report of the use of a broad range PCR to detect causal organisms in a series of patients with empyema

- Use of the broad range PCR increases detection rate of causal organisms from $18.7 \%$ using culture alone, to $75 \%$ using both techniques

- There is complete concordance in organisms when identified both by culture and this molecular technique, but additional organisms are detected by PCR

- The overall pattern of causal organisms in empyema is unchanged and unlikely to be the explanation for the increasing incidence; however, some unusual organisms can be identified using this molecular technique 
have been culture positive, as culture is the reference standard against which to compare. However, culture only gave a sensitivity of $18.7 \%$. Sensitivity has therefore been defined in samples of pleural empyema from children who have previously received more than one day of antibiotics. Earlier in the illness, or with less antibiotic treatment, the sensitivity of the PCR is likely to be higher.

In summary, this study has shown that the use of a molecular non-culture technique (broad range $16 \mathrm{~S}$ rDNA PCR) improves organism detection rate from pleural fluid in children with empyema. Even after the commencement of antibiotics the causative organisms may be detected in $68.7 \%$ of cases. The majority of organisms detected were as expected, $S$ pneumoniae, $S$ pyogenes, $S$ aureus, and anaerobes accounting for most cases. These results suggest that most of the increase in paediatric empyema is not accounted for by unusual organisms. We do not suggest that this technique should replace culture, but that it is a beneficial adjunct, especially after prior antibiotic therapy, and little clinical improvement. The assay can be offered as a routine service in a specialist laboratory, and with a turnaround time of approximately 48 hours, a result can be obtained sufficiently quickly to allow appropriate alterations in management, whereby a change to more narrow spectrum antibiotics may be made soon into the patient's in-patient stay.

\section{Authors' affiliations}

S Saglani, C Wallis, Department of Respiratory Paediatrics, Great Ormond Street Hospital for Children, Great Ormond Street, London, UK K A Harris, J C Hartley, Department of Microbiology, Great Ormond Street Hospital for Children, Great Ormond Street, London, UK

\section{REFERENCES}

1 Playfor SD, Smyth AR, Stewart RJ. Increase in incidence of childhood empyema. Thorax 1997;52:416-21.
2 Rees JH, Spencer DA, Parikh D, et al. Increase in incidence of childhood empyema in West Midlands, UK. Lancet 1997;349:402.

3 Thompson A, Reid A, Shields M, et al. Increased incidence in childhood empyema thoracis in Northern Ireland. Ir Med J 1999;92:438.

4 Byington CL, Spencer LY, Johnson TA, et al. An epidemiological investigation of a sustained high rate of pediatric parapneumonic empyema: risk factors and microbiological associations. Clin Infect Dis 2002;34:434-40.

5 Buckingham SC, King MD, Miller ML. Incidence and etiologies of complicated parapneumonic effusions in children, 1996 to 2001. Pediatr Infect Dis J 2003;22:499-504.

6 Chen KY, Hsueh PR, Liaw Y, et al. A 10-year experience with bacteriology of acute thoracic empyema. Emphasis on Klebsiella pneumoniae in patients with diabetes mellitus. Chest 2000;117:1685-9.

7 Eltringham G, Kearns A, Freeman R, et al. Culture-negative childhood empyema is usually due to penicillin-sensitive Streptococcus pneumoniae capsular serotype 1. J Clin Microbiol 2003;41:521-2.

8 Thomson $\mathbf{A H}$, Hull J, Kumar MR, et al. Randomised trial of intrapleural urokinase in the treatment of childhood empyema. Thorax 2002;57:343-7.

9 Lu J-J, Perng C-L, Lee S-Y, et al. Use of PCR with universal primers and restriction endonuclease digestions for detection and identification of common bacterial pathogens in cerebrospinal fluid. J Clin Microbiol 2000:38:2076-80

10 Rantakokko-Jalava K, Nikkari S, Jalava J, et al. Direct amplification of rRNA genes in diagnosis of bacterial infections. J Clin Microbiol 2000;38:32-9.

11 Trotha R, Hanck T, Konig W, et al. Rapid ribosequencing-an effective diagnostic tool for detecting microbial infection. Infection 2001;29:12-16.

12 Nikkari S, Lopez FA, Lepp PW, et al. Broad-range bacterial detection and the analysis of unexplained death and critical illness. Emerg Infect Dis 2002;8:188-94.

13 Yamamoto Y. PCR in diagnosis of infection: detection of bacteria in cerebrospinal fluids. Clin Diagn Lab Immunol 2002;9:508-14.

14 Harris KA, Fidler KJ, Hartley JC, et al. Unique case of Helicobacter sp. osteomyelitis in an immunocompetent child diagnosed by broad-range $16 \mathrm{~S}$ PCR. J Clin Microbiol 2002;40:3100-3.

15 Harris KA, Hartley JC. Development of a broad-range 16S ribosomal DNA PCR for use in the routine diagnostic clinical microbiology service. J Med Microbiol 2003;52:685-91

16 Altman DG. Practical statistics for medical research. London: Chapman \& Hall, 1991:410-19.

17 Munglani R, Kenney IJ. Paediatric parapneumonic effusions: a review of 16 cases. Respir Med 1991;85:117-19.

18 Hardie W, Bokulic R, Garcia VF, et al. Pneumococcal pleural empyemas in children. Clin Infect Dis 1996;22:1057-63.

19 O'Neill AM, Gillespie SH, Whiting GC. Detection of penicillin susceptibility in streptococcus pneumoniae by pbp2b PCR-restriction fragment length polymorphism analysis. J Clin Microbiol 1999;37:157-60.

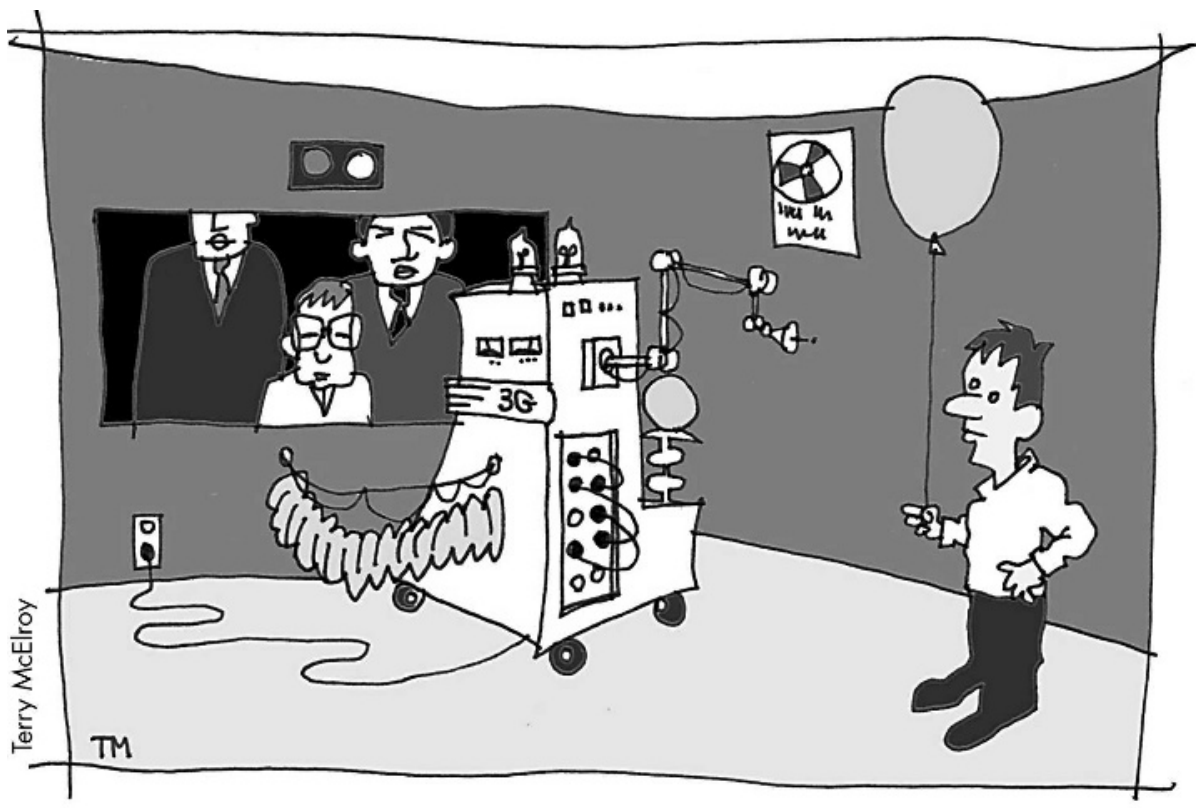

